\title{
Full-Dose Chemotherapy for Esophageal Cancer Patient under Hemodialysis
}

\author{
Akane Kurisu $^{a}$ Toshihiko Hata ${ }^{b}$ Akira Owadab \\ Departments of a Surgery and b Nephrology, Musashino Red Cross Hospital, Tokyo, J apan
}

Dear Sir,

Protocol of chemotherapy, especially optimal dose of cisplatin (CDDP), is not yet well established for esophageal cancer patients under hemodialysis. We report here a successful treatment of advanced esophagus cancer with a full-dose chemotherapy and radiation therapy.

A 68-year-old man, who was on maintenance hemodialysis for 7 years, complained of dysphagia in November 1999. Endoscopic examination revealed Borrmann 1 type tumor at the middle portion of the esophagus. Pathological examination of the biopsy specimen confirmed squamous cell carcinoma. Computed tomographic scan of the chest showed swelling of the paratracheal lymph nodes suggesting metastasis.

Because the patient abhorred our recommendation to have the operation, chemoradiation therapy was initiated. Chemotherapy consisted of short-lasting $1 \mathrm{~h}$ infusion of cisplatin $50 \mathrm{mg}$ on the first day and 5-fluorouracil (5-FU) $500 \mathrm{mg} /$ day as continuous intravenous infusion from days 1 to 5 . Administration of cisplatin was started just $1 \mathrm{~h}$ before hemodialysis. Four cycles of this therapy were performed at 2 week intervals. Synchronizing to the four cycles of chemotherapy, combined radiotherapy of total 64 Gy was consecutively performed on weekdays. During the whole treatment period, hemodialysis sessions were maintained at three times a week without any technical modification. Direct treatment-related toxic effects were minimal. At the endoscopic examination after the four cycles of chemo- therapy and radiation therapy, the tumor had completely disappeared. However, biopsy from the scar lesion showed slight cancer cell nests. These results encouraged us to perform an additional two cycles of chemotherapy under almost the same protocol, only increasing the dose of cisplatin from 50 to $80 \mathrm{mg}$ and 5-FU from 500 to $1,000 \mathrm{mg}$. Again, no grave adverse effects were observed in these two cycles of chemotherapy.

Total plasma platinum levels were measured by atomic absorption spectrometer. The mean total platinum levels at the end of an infusion of 50 and $80 \mathrm{mg}$ cisplatin were $2.68 \mu \mathrm{g} / \mathrm{ml}(\mathrm{n}=4)$ and $3.06 \mu \mathrm{g} / \mathrm{ml}(\mathrm{n}=2)$, respectively. The peak total platinum level never exceeded $3.16 \mu \mathrm{g} / \mathrm{ml}$.

Follow-up endoscopic examinations, performed biannually after six cycles of chemotherapy, revealed only scar at the previous tumor lesion of the esophagus. All the biopsy specimens failed to prove any cancer cells. Additionally, computed tomographic scan of the chest and abdomen showed no sign of recurrence, which evidenced complete response of the chemoradiation therapy for advanced cancer of the esophagus. Two years and 8 months after the onset of the symptoms, the patient is asymptomatic and enjoying his social life.

The excellent results of our case suggest that full-dose chemotherapy might be available for hemodialyzed cancer patients. It is difficult to speculate the reason why our patient with advanced esophagus cancer under hemodialysis is surviving more than 2 years with no signs of local recurrence and metastasis. Tanabe et al. [1] reported that the clearance of total platin made no difference between HD and non-HD patients, though the clearance of free platin (free-pl) was smaller in the HD patients than in the non-HD patients resulting in a 5-fold increase in free-pl exposure in HD patients. However, no severe bone marrow suppression was observed. Much longer time of contact between free-pl and cancer, in other words, much larger area under curve (AUC) of free-pl, might be contributory to the effectiveness of the chemotherapy.

However, there are little basic and clinical data [2,3], it is necessary to accumulate much more data to build up an established protocol of chemotherapy for the cancerburdened patients under hemodialysis.

\section{References}

1 Tanabe N, Goto M, Morita H, Gotu T, Inagaki J, Yamanaki N, Kimura K: Pharmacokinetics of cis-diammine-dichlor-platin in a hemodialysis patient. Cancer Invest 1991;9:629-635.

2 Rebibou JM, Chauffert B, Dumas M, Mousson C, Bone MC, Tanter Y, Rifle G: Combined chemotherapy and radiotherapy for esophageal carcinoma in a hemodialyzed patient. Nephron 1996;74:611-612.

3 Suwata J, Hiraga S, Hida M, Takamiya T, Iida $\mathrm{N}$, Satou T: Study on changes in plasma platinum concentration after administration of CDDP to maintenance hemodialysis patients (in Japanese). Jpn J Cancer Chemother 1988; 15:243-247.

\section{KARGER}

Fax +41613061234

E-Mail karger@karger.ch

www.karger.com
(C) 2002 S. Karger AG, Basel

0028-2766/02/0924-0960\$18.50/0

Accessible online at:

www. karger.com/journals/nef
Akane Kurisu, MD

Department of Surgery, Musashino Red Cross Hospital

1-26-1 Kyounanchou Musashino-shi

Tokyo 180-8610 (Japan)

Tel. +81 042232 3111, Fax +81 042232 9551, E-Mail tssjs@musashino.jrc.or.jp 